\author{
東京湾産シ +コの脂質組成について \\ 菊地 嶺* ·原口明郎 ${ }^{* *} \cdot$ 前沢伸和 ${ }^{* * *}$ \\ (1966 年 3 月 4 日受理)
}

\title{
LIPID COMPONENTS OF SQUILLA IN TOKYO BAY
}

\author{
Ryo KikUChI*, Akio HaRaguCHI** \\ and Nobukazu MAEZAWA***
}

Recently, abnormally colored squillae, Squilla oratoria, the body color of which are yellowish gray instead of purplish brown, are found frequently among the catches in Tokyo Bay. The cause of discoloration seems to be ascribed to the environmental sea water which has been polluted strongly by coastal industries.

Some chemical natures and composition of lipid of the discolored squillae were compared with those of normal squillae, and the following results were obtained:

1. Any difference in the lipid content, refractive index of the lipid, and neutralization value of fatty acids could not be observed between the two samples. The lipid of the discolored sample, however, showed higher saponification and iodine values and lower content of unsaponifiable matters as compared to those of normal one.

2. Fatty acids in discolored sample contained less amount of $\mathrm{C}_{12: 0}, \mathrm{C}_{14: 1}, \mathrm{C}_{22: 5}$ and more $\mathrm{C}_{18: 4}(?), \mathrm{C}_{20: 2}(?), \mathrm{C}_{24: 1}$ fatty acid than the normal, although a further confirmation seems to be necessary.

3. No significant difference in carotenoid content was observed between the tow samples.

4. Lipid in discolored sample contained far less cholesterol than the normal. As regards the content of 7-dehydrocholesterol, however, no significant difference was found between the two samples.

近年東京湾において漁獲されるシャコの5ち、シャュ固有の紫褐色の色調が退色し黄厥色のものが多く出

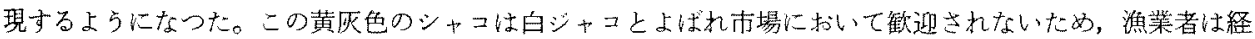
済的に打撃を5けているが，い亲だに対策は講じられていない。

元来，シャコは污染海水に強く，東京湾の内奥部のごとき污染のはなはたしい水域にも相当に棲息してい るため，かかる水域に抢ける漁獲物としては，次第に重要度が高京つている。

漁業者の談を総合すると，退色のいちじるしいシャコは概して人口密集地带に近く，污染度の高い水域に

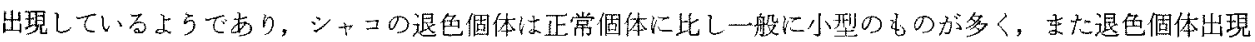
の頻度は應䀧である6月より以前に多いともいわれている。ただし，これらはいずれも実際の調查にもと

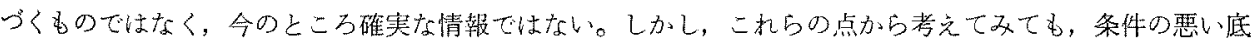

*東海区水鷹研究所 (Tokai Reg. Fish. Res. Lab., Kachidoki, Chuo-ku, Tokyo, Japan) 東海区 水主研究所等績B第 449 号

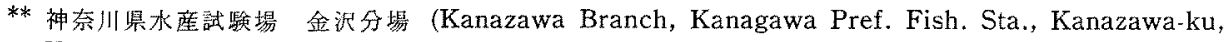
Yokohama)

*** 日本大学農獣医学部 (The College of Agriculture and Veterinary Medicine, Nihon Univ., Tokyo) 
Table 1. Samples of squillae, caught in May, 1964 at Koyasuhama, Kanagawa Pref.

\begin{tabular}{c|c|c|c}
\hline $\begin{array}{c}\text { Body color of } \\
\text { the sample }\end{array}$ & Number of squillae & $\begin{array}{c}\text { Total weight } \\
\mathrm{g}\end{array}$ & $\begin{array}{c}\text { Average body weight } \\
\mathrm{g}\end{array}$ \\
\hline Normal (Purplish brown) & 21 & 968.0 & 46.1 \\
Abnormal (Yellowish gray) & 21 & 973.2 & 46.3 \\
\hline
\end{tabular}

Table 2. Oil content and properties of the lipids from squillae.

\begin{tabular}{l|c|c|c|c|c|c|}
\hline \multicolumn{1}{c}{ Sample } & $\begin{array}{c}\text { Oil content } \\
\%\end{array}$ & $\begin{array}{c}\text { Refractive } \\
\text { index }\end{array}$ & $\begin{array}{c}\text { Saponification } \\
\text { value }\end{array}$ & Iodine value & $\begin{array}{c}\text { Neutralization } \\
\text { value }\end{array}$ & $\begin{array}{c}\text { Unsaponifiables } \\
\%\end{array}$ \\
\hline Normal & 1.52 & 1.4769 & 156.2 & 140.5 & 170.8 & 9.37 \\
Abnormal & 1.53 & 1.4769 & 159.8 & 146.8 & 169.5 & 9.04 \\
\hline
\end{tabular}

買，濁度の高い游水などのため，生活機能に何らかの巽常をきたすことが退色の原因ではないかと想像され

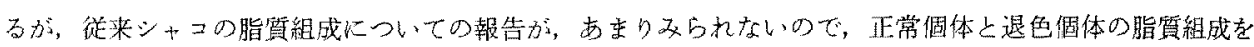
比輘してみた。元の結果孝報告する。

また，生体中の脂質成分は，その生物の生活機能の正常，異常を反映することは，福田ら”のスッポン体

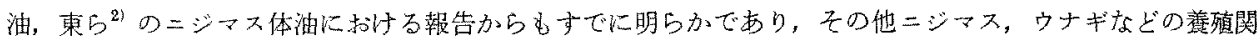
同の報告, 談話などの類にも数多く欢らる。

\section{実鈳結果および考察}

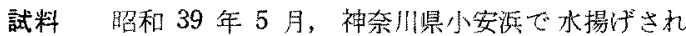
たものの中から，正常個体，退色個体それぞれ 21 尾を選び 実駼比供した。Table 1 に重量, 平均体重を示した。

試料をてれぞれ水洗した後，チョッパーにか忛て細切し， アセトンて䑫水後，エーテル抽出をおこない，アセトン抽出 物とエーテル抽出物とをあ奻せて溶剂を留去し，得た脂筫に ついて，以下の害験をおこなつた。

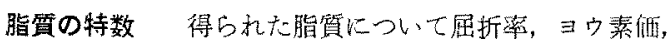
ケン化侢, 不ヶン化物含量および脂肪酸の中和湖を常法によ り測定した。Table 2 にみられるように，含油泺，油の屈折 率，混合脂肪酸の中和洒においては両試料間に差はないが， ケン化価，ヨウ素洒は退色個体が高く，不ヶン化物含量は退

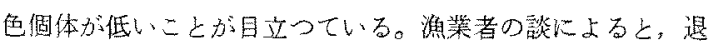

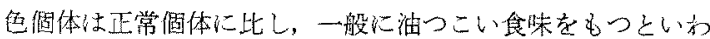
れるが，本試料関寸る限りでは，含油率には美がみられな 力八:。

脂肪酸組成脂肪酸組成をガスクロマトグラフィーによ つて模した結果を Table 3 に示与。退色個体㛎正常個体上 り甩 $\mathrm{C}_{12: 0}, \mathrm{C}_{14: 1}, \mathrm{C}_{22: 5}$ が少なく, $\mathrm{C}_{18: 4}$ (?), $\mathrm{C}_{20: 2}$ (?), $\mathrm{C}_{24: 1}$ が多い点が目立つてい万が，これらの点は今娞さらに倹討を

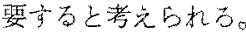

カロチノイド組成闻試料の可視部吸光曲線は Fig. 1 ほ示すごとく，アスタキ+ンチンに相当する $465 \sim 470 \mathrm{~m} \mu$
Table 3. Fatty acid composition of the lipids from squillae.

\begin{tabular}{|c|c|c|}
\hline Fatty acid & Normal \% & Abnormal \% \\
\hline $\mathrm{C}_{10: 0}$ & 0.7 & 0.5 \\
\hline $\mathrm{C}_{14: 0}$ & 6.3 & 5.8 \\
\hline $\mathrm{C}_{14: 1}$ & 2.0 & 1.4 \\
\hline $\mathrm{C}_{15: 0}$ & 1.4 & 1.4 \\
\hline $\mathrm{C}_{15: 1}$ & 0.7 & 0.6 \\
\hline$C_{16: 0}$ & 15.1 & 14.3 \\
\hline$C_{16: 1}$ & 11.5 & 10.2 \\
\hline $\mathrm{C}_{17: 0}$ & 2.7 & 2.6 \\
\hline $\mathrm{C}_{17: 1}$ & 2.0 & 2.0 \\
\hline$C_{18: 0}$ & 4.6 & 5.1 \\
\hline $\mathrm{C}_{18: 1}$ & 17.1 & 16.8 \\
\hline $\mathrm{C}_{18: 2}$ & 1.9 & 2.1 \\
\hline $\mathrm{C}_{18: 3}$ & 1.0 & 1.1 \\
\hline $\mathrm{C}_{18: 4}(?)$ & 0.6 & 1.0 \\
\hline $\mathrm{C}_{20 \cdot \mathrm{I}}$ & 3.9 & 4.6 \\
\hline $\mathrm{C}_{20: 2}(?)$ & 0.6 & 0.8 \\
\hline $\mathrm{C}_{20: 4}$ & 2.9 & 3.3 \\
\hline $\mathrm{C}_{20: 5}$ & 10.5 & 10.4 \\
\hline $\mathrm{C}_{22: 5}$ & 2.5 & 1.6 \\
\hline $\mathrm{C}_{22: 6}$ & 10.8 & 12.2 \\
\hline $\mathrm{C}_{24: 1}$ & 1.1 & 2.3 \\
\hline
\end{tabular}




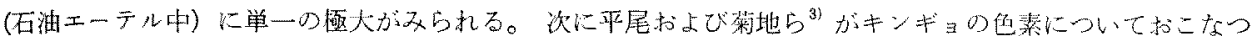

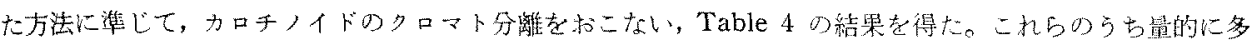
い电のを示せば Table 5 の通りである。すなわり，耐試料とも力口チノイドは大部分フスタキサンチンか

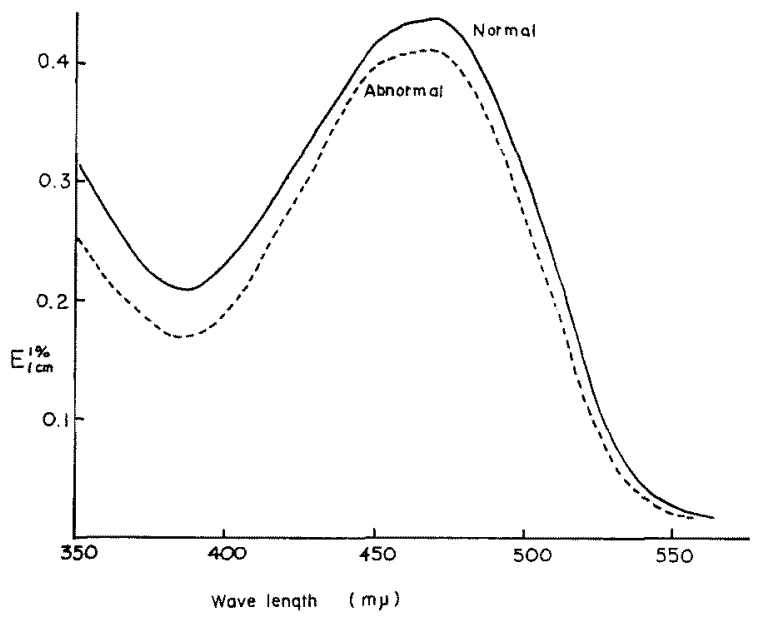

Fig. 1. Absorption curve of the oil from squillae. Measured in petroleum-ether solution.

Table 4. Chromatographic separation of the carotenoids from squillae.

\begin{tabular}{|c|c|c|c|c|c|c|c|c|c|}
\hline \multirow{3}{*}{$\begin{array}{c}\begin{array}{c}\text { Fraction } \\
\text { number }\end{array} \\
1\end{array}$} & \multirow{2}{*}{$\begin{array}{l}\text { Eluents; mixing } \\
\text { proportions of } \\
\text { petroleum-ether: } \\
\text { ethyl ether. }\end{array}$} & \multicolumn{8}{|c|}{ Absorption maxima observed in petroleum-ether. $(\mathrm{m} \mu)$} \\
\hline & & \multicolumn{4}{|c|}{ Normal } & \multicolumn{4}{|c|}{ Abnormal } \\
\hline & $10: 0$ & & 420 & 446 & 472 & 387 & $(420)^{*}$ & 445 & 472 \\
\hline 2 & $10: 0$ & & & 447 & 480 & & $(420)$ & & $(473)$ \\
\hline 3 & $9.5: 0.5$ & $(386)$ & (421) & $(446)$ & & 396 & 422 & 448 & \\
\hline 4 & $9.5: 0.5$ & & $(420)$ & 447 & & (395) & $(422)$ & 446 & $(479)$ \\
\hline 5 & $9: 1$ & (395) & $(420)$ & $(444)$ & & & & 453 & \\
\hline 6 & $8: 2$ & $(395)$ & $(421)$ & $(443)$ & & 396 & $(419)$ & $(442)$ & \\
\hline 7 & $8: 2$ & $(396)$ & & $(442)$ & & 396 & 419 & 440 & $(470)$ \\
\hline 8 & $7: 3$ & $(402)$ & & $(450)$ & & & & 454 & \\
\hline 9 & $5: 5$ & $(400)$ & & (443) & $(471)$ & $(396)$ & & & \\
\hline 10 & $3: 7$ & $(400)$ & & $(441)$ & $(470)$ & $(400)$ & $(420)$ & $(443)$ & $(472)$ \\
\hline 11 & $0 \quad: 10$ & & 421 & 445 & 471 & & $(421)$ & 445 & 472 \\
\hline 12 & $\begin{array}{l}\text { Ether containing } \\
\text { acetic acid } 3 \%\end{array}$ & & & & & $(396)$ & $(419)$ & $(445)$ & $(476)$ \\
\hline 13 & " & & & & & & & & 64 \\
\hline 14 & " & & & & 66 & & & & 66 \\
\hline 15 & $"$ & & & & 69 & & & & 66 \\
\hline 16 & $"$ & & & & 65 & & & & 60 \\
\hline 17 & $"$ & $\ldots \ldots$ & & & $\cdots \cdots$ & & & & 68 \\
\hline
\end{tabular}

* Figures in parentheses represent an approximate one because of lack of absorption maxima. 
Table 5, Carotenoid content in squillae on wet bases.

\begin{tabular}{|c|c|c|c|c|c|}
\hline \multirow[b]{2}{*}{ Sample } & \multicolumn{2}{|c|}{ Carotenoid in oil } & \multicolumn{2}{|c|}{$\begin{array}{l}\text { Amount of carotenoid } \\
\text { per individual of samples }\end{array}$} & \multirow[b]{2}{*}{$\frac{\text { Astaxanthin }}{\text { Lutein-like pigment }}$} \\
\hline & $\begin{array}{c}\text { Lutein-like } \\
\text { pigment } \\
\mu \mathrm{g} / \mathrm{g}\end{array}$ & $\begin{array}{c}\text { Astaxanthin } \\
\mu \mathrm{g} / \mathrm{g}\end{array}$ & $\begin{array}{c}\text { Lutein-like } \\
\text { pigment } \\
\mu \mathrm{g}\end{array}$ & $\begin{array}{c}\text { Astaxanthin } \\
\mu \mathrm{g}\end{array}$ & \\
\hline Normal & 4.8 & 167 & 3.5 & 117 & 33.4 \\
\hline Abnormal & 7.6 & 157 & 5.4 & 111 & 20.6 \\
\hline
\end{tabular}

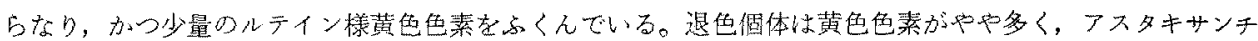

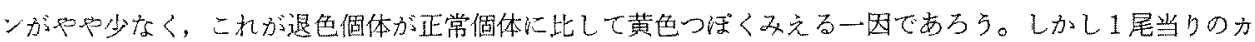
ロチノイド総量は両試料閶にほとんど差がない。この点から考光て，シャコの退色個体が正常個体に比して

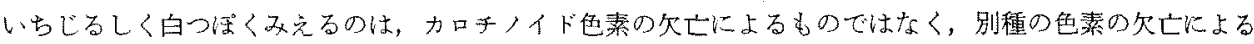

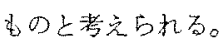

ステロイトの分画不ケン化物を冷タタノール処理して析出する不溶物を集め，さらにメタノ一ルによ る再結を繰り返えして混合ステロイドを得た。混合ステロイドの含麗はTable 6 に示すごとく湜色個体は 正常固体に比しいるしるるしく少ない。次にジギトニン沈激法によりコレスデールを定量したとこる，コレ

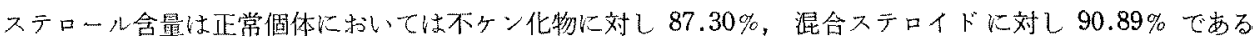
のに，退色個体に扎てはそれぞれ 52.77 ，76.56\% で西り，いちじるい差が認められた。

Table 6. Steroid content of squillae.

\begin{tabular}{l|c|c|c|c|c|c}
\hline \multirow{3}{*}{ Sample } & \multicolumn{2}{|c|}{ Steroid } & \multicolumn{2}{|c|}{ Cholesterol } & \multicolumn{2}{c|}{7 -Dehydrocholesterol } \\
\cline { 2 - 7 } & in oil & $\begin{array}{c}\text { unsaponifiables } \\
\text { in }\end{array}$ & $\begin{array}{c}\text { in } \\
\text { unsaponifiables }\end{array}$ & $\begin{array}{c}\text { in } \\
\text { steroid } \\
\%\end{array}$ & $\begin{array}{c}\text { in } \\
\text { unsaponifiables } \\
\%\end{array}$ & $\begin{array}{c}\text { in } \\
\text { steroid }\end{array}$ \\
\hline Normal & 9.00 & 96.05 & 87.30 & 90.89 & 0.82 & 0.86 \\
Abnormal & 6.23 & 68.92 & 52.77 & 76.56 & 0.75 & 1.09 \\
\hline
\end{tabular}

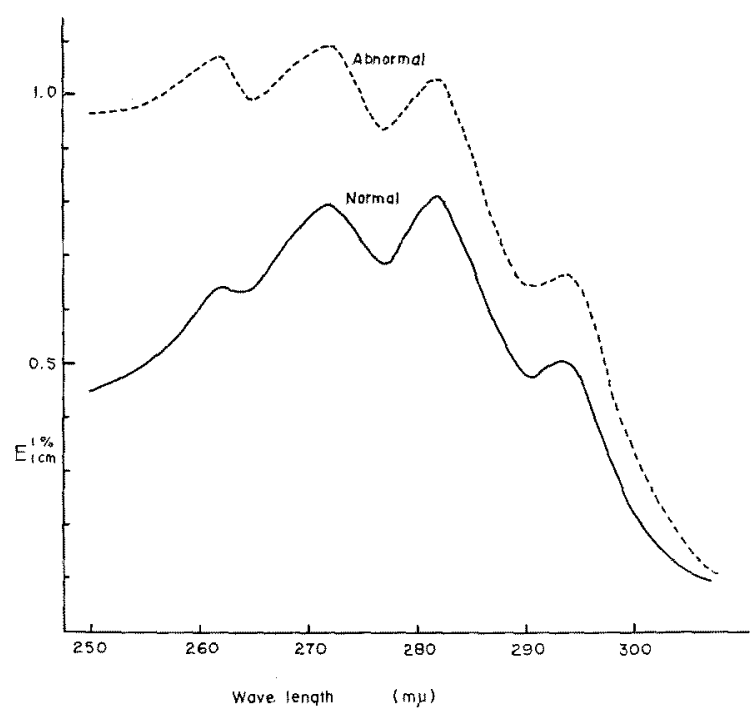

Fig. 2. Absorption curve of the steroid from squillae. Measured in ethyl alcohol solution. 
まだ，混合ステロイドの紫外部吸収曲線は Fig. 2 に示すごとく 272,282 および $294 \mathrm{~m} \mu$ (EtOH 中)

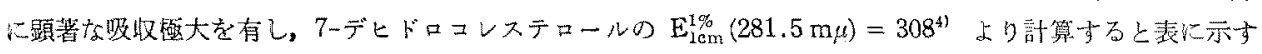
ごとさ值となり，7ーデとドロコレステロールにおいては，正常個体，退色個体間に大きな差璱められず， 混合ステロイド中に7ーデヒドロコレステロールの占める割合が泿色個体において僅かに高いこととなる。

要 約

東京湾におけるシャ二の很色個体の脂質を正常㧽体のそれと比較して次の知見を得た。

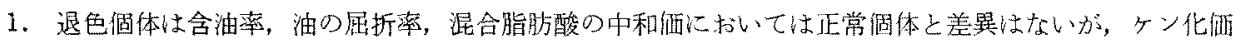
は僅かに高く，ヨウ素洒はかなり高く，不ヶン化物含量はやや低かつた。

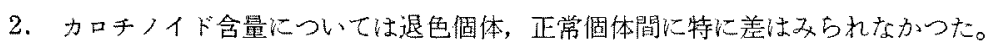

3. 退色個体は正常個体よりもコレステロール含量がいちじるしく低いが，7ーデヒドロコレステロールの 含量には差がなかつた。

本穾験について終始御慜第なる御指導をいただいた東海区水産研究所平尾秀一生化学研究空舆に感謝の意 を䘚しす。

文献

1) 福田博業・黑木 暘：本誌，26，1123 1127 (1960).

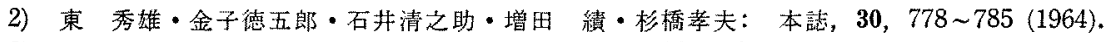

3) 平尾秀一・菊地 嶺 - 田口脩子：本誌，29，371 381 (1963).

4) M. Glover, J. Glover and R. A. Morton: Biochem. J., 51, 1 9 (1952). 